AMERICAN JOURNAL BIOTECHNOLOGY AND MOLECULAR SCIENCES

ISSN Print: 2159-3698, ISSN Online: 2159-3701, doi:10.5251/ajbms.2011.1.1.17.29

(C) 2011, ScienceHuß, http://www.scihub.org/AJBMS

\title{
Resemblance between somatic embryo-derived plantlets and plantlets bearing cotyledons of Theobroma cacao L., in relation to their growth in the greenhouse using the typology
}

\author{
Auguste Emmanuel Issali ${ }^{1},{\text { Abdoulaye } \text { Traore }^{2}, \text { Emile Minyaka }^{3} \text {, Desire Allou }}^{4}$, \\ Abdourahamane Sangare ${ }^{5}$, Nafan Diarrassouba ${ }^{6}$, Thierry T. Lékadou ${ }^{1}$, Mah Toure ${ }^{7}$. \\ ${ }^{1}$ Station de Recherche sur le Cocotier Port Bouët Marc Delorme. CNRA. 07 BP 13 Abidjan \\ 07. Côte d'Ivoire. \\ ${ }^{2}$ Products Development and Research Scientific. Mars Snackfood US. 295 Brown Street. \\ Elisabethtown. PA 17022. abdoulaye.traore@effem.com \\ ${ }^{3}$ Department of Biochemistry, Faculty of Sciences, University of Douala P.O. Box 24157 \\ Douala - Cameroon. eminyaka@yahoo.fr \\ ${ }^{4}$ Station de Recherche sur le Palmier à Huile La Mé. CNRA. 13 BP 789 Abidjan 13. Côte \\ d'Ivoire. desire.allou@gmail.com \\ ${ }^{5}$ Coordonnateur Coraf-Wecard. Abou.sangare@coraf.ci \\ 'Unité Régionale de l'Enseignement Supérieur de Korhogo BP 1328, Côte d'Ivoire. \\ nafandiarra@yahoo.fr \\ ${ }^{7}$ Laboratoire Central de Biotechnologies (LCB). Centre National de Recherche Agronomique \\ (CNRA) ; 01 BP 1740 Abidjan 01, Côte d'Ivoire. mahtoured@yahoo.fr
}

\begin{abstract}
To analyse the resemblance within genotypes and culture medium effects relatively to somatic embryos (SE) production as well as among the plantlet types, especially SE-derived plantlets and seedlings bearing cotyledons, their typing was performed. Staminodes and petals deriving from two hybrids (L126-A3 and L233-A4) and one clone (C151-61) were used. The clone SCA6 was used as positive control. Three culture media PCG1, PCG3 and PCG4 only differing from one another by hormonal concentrations were used. Five variables for tissue culture and vegetative development in the greenhouse were measured. The SE production and vegetative development of the plantlets regenerated from SE were compared. The Principal Component Analysis, Cluster Hierarchical Analysis and Z test allowed the structuring of the variables, genotypes, culture media effect, explant nature, plantlets type and separating the averages, respectively. It emerges from results that genotype C151-61 both showed better callogenic and embryogenic abilities. These abilities were comparable to those of control SCA6. This finds an explanation from kinship existing between the two. Likewise, C151-61 expressed better vegetative development than the two other genotypes. Its growth in the greenhouse was higher than that of control SCA6. This might be due to geographical position in the greenhouse of the plantlets proceeding from these two genotypes. The SE-derived plantlets better developed than cotyledon-amputed plantlets. It seems that the stress undergone by the latter is the reason. The resemblance between the SE-derived plantlets and plantlets bearing cotyledons was much strong. So their production costs would be comparable. We can continue to produce and conduct the SE-derived plantlets in the greenhouse and nursery awaiting their assessing in the large field trials.
\end{abstract}

Key words : typing, proximity relatively to growth, cotyledon-amputed plantlets, production cost.

INTRODUCTION

Chocolate tree is a cross-pollinated, perennial and diploid plant of the Malvaceae (Whitlock et al., 2001).
It provides some substantial incomes to numerous smallholders of the developing countries (Wood and Lass, 1985). With a production of about $43 \%$, Côte d'lvoire is the top of the world cocoa production 
(ICCO, 2000). About $6 \%$ of national territory are cultivated with cocoa trees. The life of more than 6 millions of persons depends on cocoa (Anonymous, 2004). Cocoa procures about $30 \%$ of global export receipts (ICCO, 2000). It participates in more than $15 \%$ at gross domestic product (ICCO, 2000). Moreover, the average yields of dry bean in farms, in the order of 250 to $500 \mathrm{Kg} / \mathrm{ha}$, are relatively low (Braudeau, 1969; Mossu, 1990; Keli et al., 2005). However, in research stations, they reach $2.5 \mathrm{t} / \mathrm{ha}$ (Clement et al., 1996). One of the ways to improve them is the clonal propagation by means of rooted cuttings and grafting from the superior genotypes (Braudeau, 1969). However, trees proceeding from these two methods present some disadvantages (Bertrand et Agbodjan, 1989; Bertrand et Dupois, 1992; Kouamanan, 2001). As an alternative, micropropagation by somatic embryogenesis was adopted (Li et al., 1998; Guiltinan and Maximova, 2000; Tan and Furtek, 2003). It is now possible to produce SE-derived plantlets from numerous genotypes (Li et al., 1998; Guiltinan and Maximova, 2000). Moreover, the growth of SE-derived plantlets in the greenhouse is slow. Such a slowness of growth would be due to lack of cotyledons that contain some nutritive reserves. These ones allow the plantlets to grow during the first stages of development. Now the lacking of cotyledons extends the duration of stay of plantlets in the greenhouse, and so increases their production cost. Indeed, the duration of regeneration of a somatic embryo from calli stretches out from 6 to 8 months (Traore et al., 2003). That of a plantlet destined at weaning in the greenhouse from a somatic embryo spreads out from 4 to 6 months. From weaning to the end of acclimatization, the duration of stay of SE-derived plantlets in the greenhouse is not less than one year. In all at least two years are necessary to put SE-derived plantlets in nursery. Now, the production cost of SE-derived plantlets including that of labour approximately amounts to $\$ 10$ US per plant (Guiltinan and Maximova, 2000). To date, on cocoa tree, no study has reported the analysis of behaviour of SE-derived plantlets based on measurements in the greenhouse. Such a study would allow the analysis of resemblance, especially between SE-derived plantlets and seedlings through their growth in the greenhouse. In the case where the growth of SEderived plantlets would be slow compared with seedlings bearing cotyledons, their production cost would be lesser.

This work aimed to analyse the resemblance among three genotypes C151-61, L233-A4 and L126-A3 of tree cocoa as well as that of two plantlet types deriving from them through the typing of their SE production and growth in the greenhouse.

\section{MATERIALS AND METHODS}

Plant material, tissue culture and growth of the plantlets in the greenhouse: All of experiments were conducted from 2002 to 2005 at the Central Biotechnology Laboratory of CNRA (Centre National de Recherche Agronomique). Two hybrid genotypes L233-A4 and L126-A3 under assessing as well as clone C151-61 were used. The clone SCAVINA6 (SCA6) was used as positive control, by reason of its high embryogenic abilities (Maximova et al., 2002; Issali et al., 2008 b). These four genotypes were characterized (Issali et al., 2008 b), but not typed.

For tissue culture, flower buds measuring 4 to $5 \mathrm{~mm}$ long were used as explants source. They were collected once a week early in the morning. Disinfection of buds, preparation of culture media and initiation of culture were carried out according to Li et al., (1998) protocol, adapted in Issali et al., (2008 a,b) and Issali et al., (2010). Three culture media PCG1, PCG3 and PCG4 were used. They only differed from one another by hormonal concentrations, but had the same hormonal balance. Thus, PCG3 (2.4 D/TDZ = $4.52 \mu \mathrm{M} / 11.35 \mathrm{nM}$ ) was the least concentrated. PCG1 (2.4 D/TDZ = 9.04 $\mu \mathrm{M} / 22.70 \mathrm{nM})$ was twofold as concentrated as PCG3. PCG4 (2.4 D/TDZ $=18.08$ $\mu \mathrm{M} / 45.40 \mathrm{nM}$ ) was fourfold as concentrated as PCG3.

The growth of SE-derived plantlets was carried out in the the greenhouse. Two treatments represented by SE-derived plantlets (SE) and cotyledon-amputed plantlets (SSC) placed in the bags were compared to control consisting of plantlets with cotyledons (SAC). These two plantlets types are devoid of nutritive reserves contained in cotyledons. The number of each genotype was reported (Table 1). Here also, for the typology of genotypes, SCA6 was used as control. However, concerning the experiment on plantlets type, these are plantlets bearing cotyledons that were used as control.

Table 1: Number of the plantlets used per genotype

\begin{tabular}{|l|c|c|c|}
\hline Genotype & SED $^{*}$ & SSC* $^{*}$ & SAC* $^{*}$ \\
\hline L233-A4 & 31 & 11 & 31 \\
\hline L126-A3 & 11 & 12 & 25 \\
\hline SCA6 & 12 & 12 & 31 \\
\hline C151-61 & 21 & 10 & 31 \\
\hline
\end{tabular}

Legend 
SED*: SE-derived plantlets; SSC*: cotyledonremoved plantlets; SAC*: plantlets bearing cotyledons.

One seed was buried in each of bags filled of soil. In all, thirty one seeds were buried in each of the bags containing soil. These bags were laid out in row (Figures 13a, 13b, 13c 13d, 13e and 13f). The measurements were carried out every three days for the first three weeks. From the fourth to the sixth week, they were achieved once a week. From the seventh to the eighth week, they were done once only. From the ninth to the fifty second week, the measurements were performed once a month.

The available plantlets number was unbalanced on account of the weak numbering of SE-derived plantlets and mortality of cotyledon-amputed plantlets after the setting of the experiment (Table 2). The plantlets were obtained from pods harvested on the concerned trees as well as their half sibs and clones.

After setting the experiment in the greenhouse, the buried seeds and SE-derived plantlets placed in bags were watered every day for the first three weeks. At the end of every week, a nutritive solution constituted of nutrients from medium of Embryos Development sugar free was used (Li et al., 1998). From the fourth week, the developed plantlets were watered every two or three days as a function of ambient temperature.

Measured variables for tissue culture and growth of the plantlets in the greenhouse: With respect to tissue culture, five variables were measured at the end of each culture on every genotype. These are : 1) callogenic explants number (Nexcal), 2) embryogenic explants number (Nexemb), 3) embryos number per embryogenic explant (Nemb), 4) embryos average per embryogenic explant (Mexemb) and 5) percentage of embryogenesis $(\mathrm{Pe})$. The first four variables have undergone the square root transformation, whereas the angular one was applied to fifth. These transformations allowed the normalization of measured distributions and equalization of variances of the sub-populations analysed.

Regarding growth of the plantlets, five variables were measured : 1) height (Height), 2) number of emitted leaves (Nbemleav), 3) length of the greatest leaf (Lengleaf) , 4) wide of the greatest leaf (Widgleaf) and 5) diameter at collar (Diamcol).

Statistical analyses: The Xlstat software version 2007.6 was used for the statistical analyses as a whole. Collected data were processed by the Principal Component Analysis (PCA), Hierarchical Cluster Analysis (HCA) and Z test. The PCA allowed the structuring of variables as well as that of individuals represented by genotypes, media and plantlets type. From this, the most relevant identified descriptors from the PCA were submitted to the HCA to confirm the initial classification resulted from the PCA, but with reduced number of the variables. The HCA was based on centred and reduced data using the Ward as aggregating method. It also allowed the assessing of the resemblance among groups from the euclidian distances of the proximity matrix. Furthermore, the explant effect was run by $Z$ test for two independent samples at $5 \%$ threshold. It was used to separate two averages once the number of the observations was higher than 30 .

\section{RESULTS}

Typing of the genotypes, culture media and explant nature for tissue culture: As regards genotype factor, the callogenic explants number (Nexcal), embryos number per embryogenic explant (Nemb) and embryos average per embryogenic explants (Mexemb) were proved to be relevant. Consequently, they were chosen in the rest of analysis to structure in three groups the genotype effect revealed by the PCA and confirmed by HCA. On the contrary, the embryogenic explants number $(\mathrm{Nexemb})$ and embryogenesis percentage $(\mathrm{Pe})$ were eliminated from the analysis. Thus, the three best variables provided the following clustering: 1) G1 formed of C151-61 and control SCA6, 2) G2 composed of L126A3 and 3) G3 constituted of L233-A4. The genotypes SCA6 and C151-61 displayed better productions of calli and SE (Figures 1, 3 and 5; Table 2).

As for culture media, the callogenic explant number, embryos number per embryogenic explant, embryos average per embryogenic explant and embryogenesis percentage were found to be the best variables able to describe the medium effect. So, they were used in the course of study to classify the medium effect in three clusters by means of the PCA. Such a classification was verified by the HCA. The embryos number per embryogenic explant was eliminated from the study later on. These three groups were: 1) G1 consisted of PCG3, 2) G2 composed of PCG1 and 3) G3 constituted of PCG4. The PCG3 medium showed a high callogenic potential, while the PCG4 expressed a high embryogenic potential (Figures 2, 4 and 6; Table 3). 
With respect to explant nature, no significant difference was recorded between petals and staminodes relatively to the callogenic explants number. The calculated averages for each of explants were 18.46 and 19.10, respectively. However, some statistical differences were evidenced on the embryos number per embryogenic explant and embryogenesis percentage of two explants. Petals favoured somatic embryogenesis more than staminodes. For each of explants, the calculated averages amounted to 0.985 and 8.181 as well as 42.64 and $85.97 \%$, respectively. On the whole, the variation coefficients varied from 9.35 to $19.03 \%$ (Table 4).
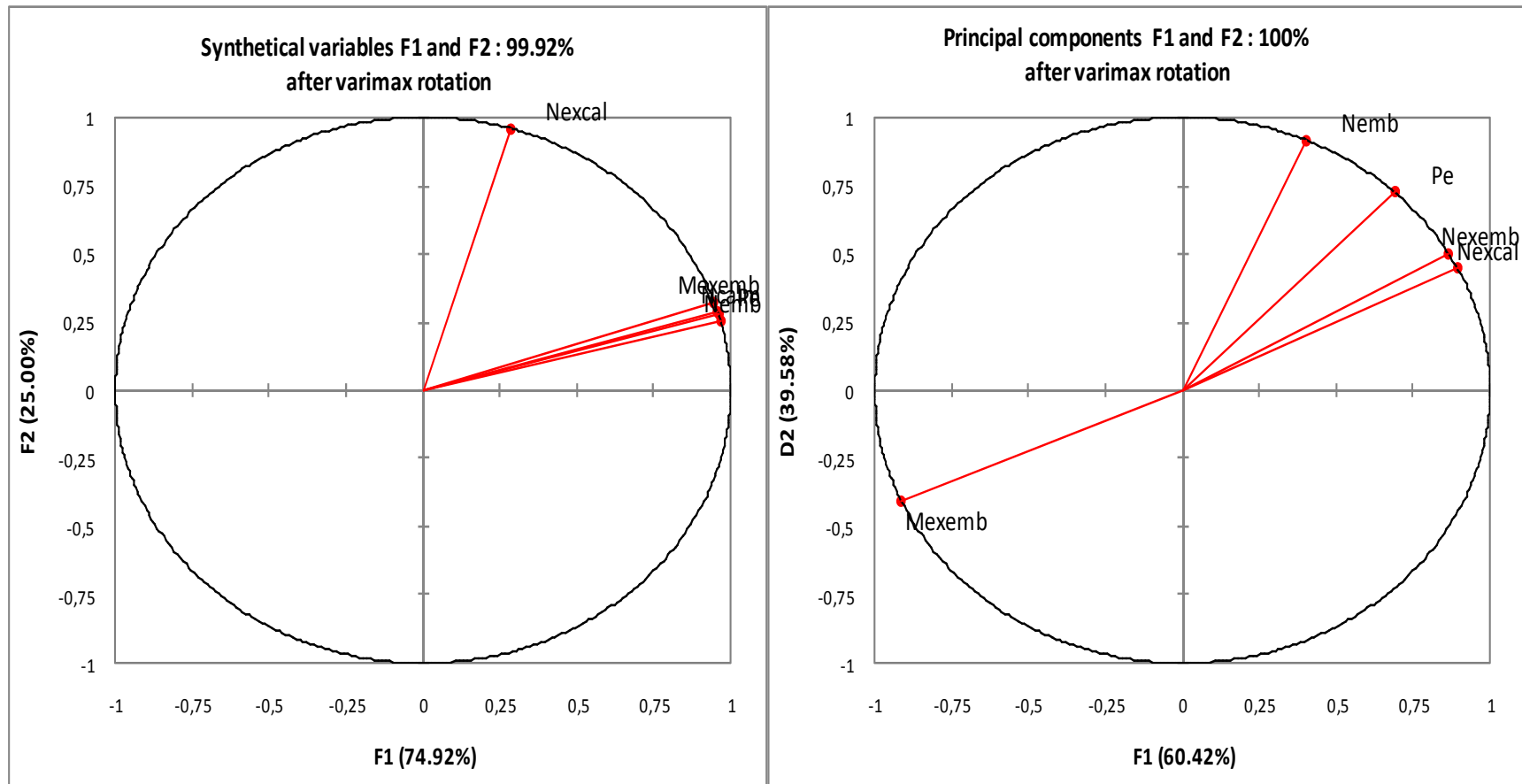

Fig 1

Fig 2
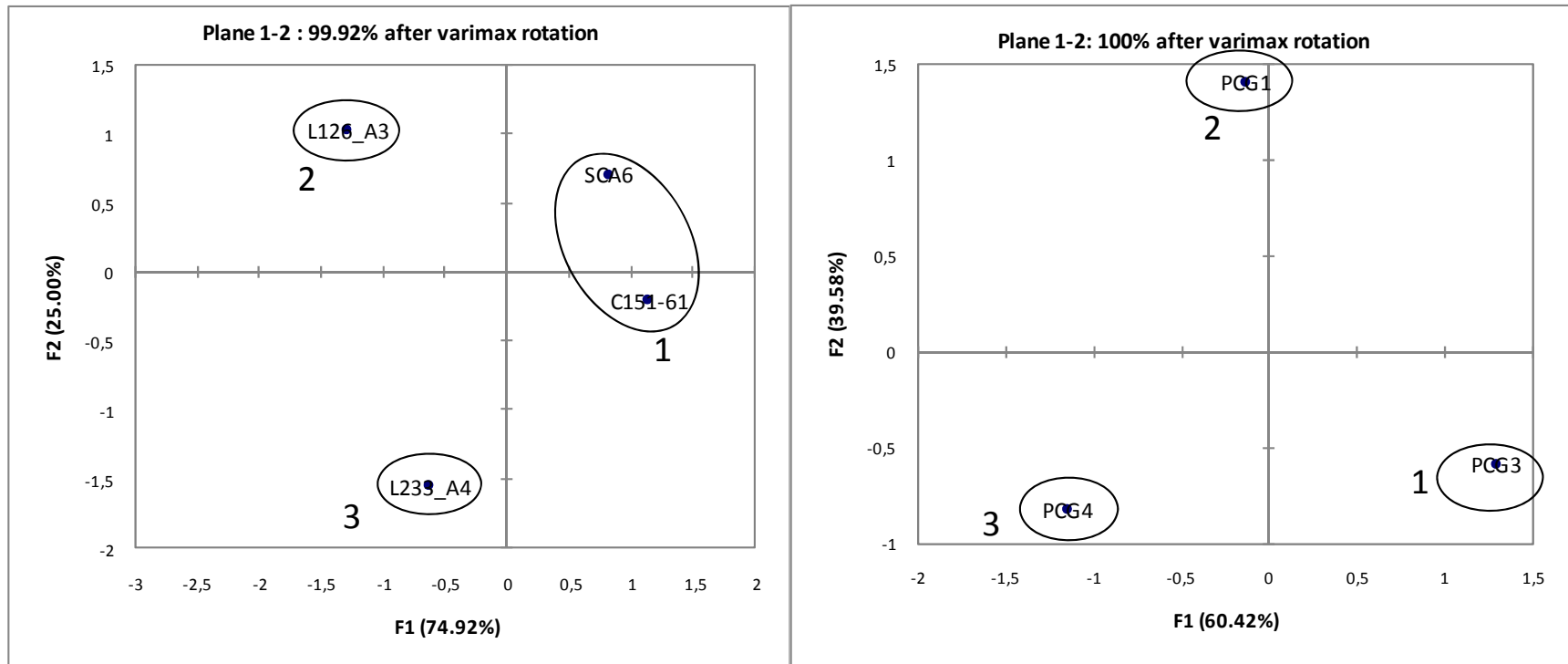

Fig 3

Fig 4 


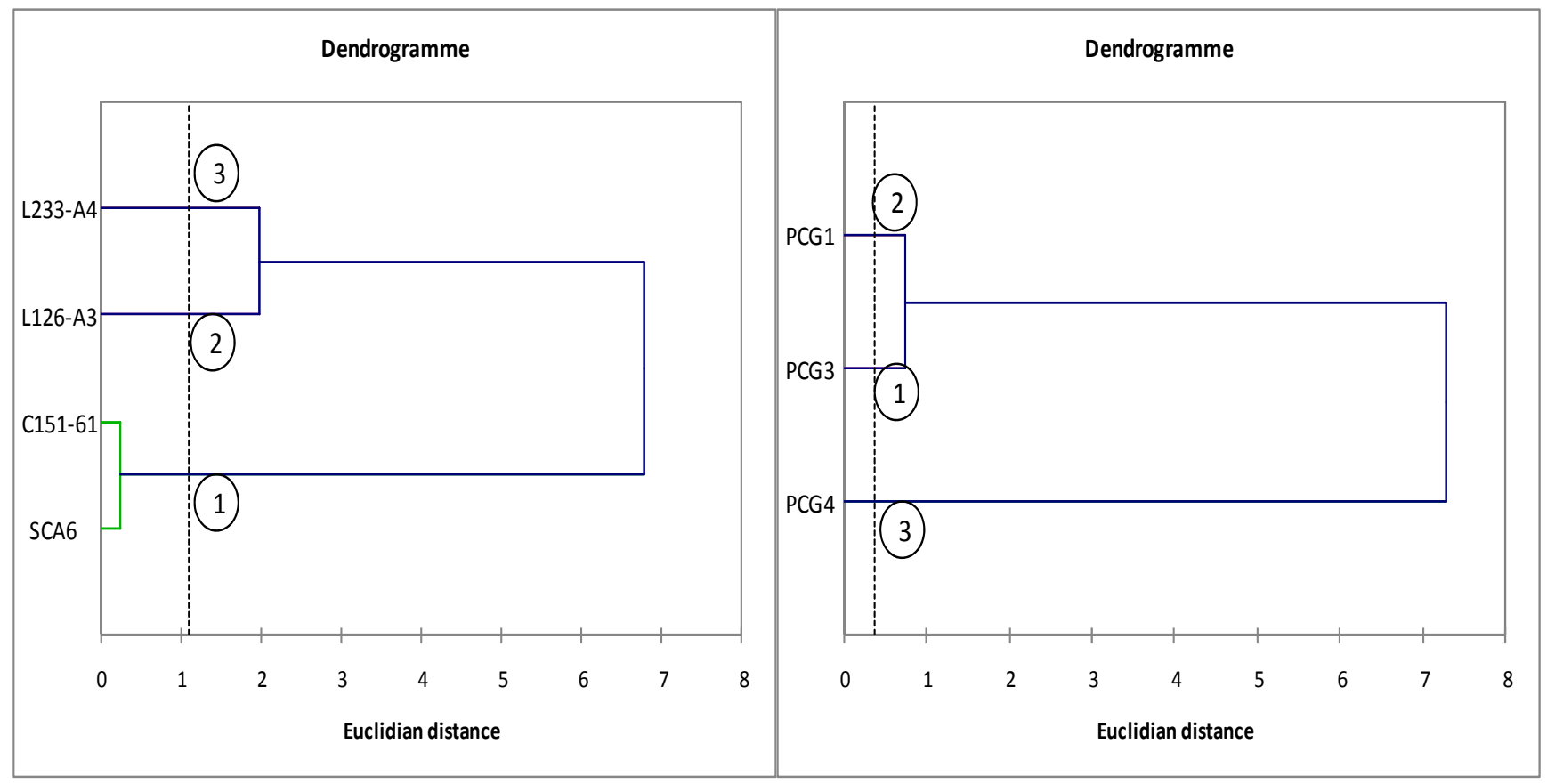

Fig 5

Fig 6

Table 2: Hierarchical classification of the genotypes from the three identified relevant descriptors for tissue culture

\begin{tabular}{|c|c|c|c|}
\hline Group Descriptor* & Nexcal & Nemb & Mexemb \\
\hline G1 (C151-61, SCA6) & 19.251 & 10.479 & 2.995 \\
\hline G2 (L126-A3) & 19.424 & 0.602 & 0.516 \\
\hline G3 (L233-A4) & 15.380 & 0.281 & 0.237 \\
\hline Average & 18.018 & 3.787 & 1.249 \\
\hline
\end{tabular}

Legend

Group : G1 (C151-61, SCA6) : First classified and identified group. G2 (L126-A3) : Second classified and identified group. G3 (L233-A4) : Third classified and identified group. Descriptor*: Nexcal : Callogenic explant number. Nemb : Embryos number per embryogenic explant. Mexemb : embryos average per embryogenic explant.

Table 3: Hierarchical classification of the effect of culture media using the three identified relevant descriptors for tissue culture

\begin{tabular}{|l|c|c|c|c|}
\hline Group & Nexcal & Nemb & Mexemb & Pe \\
\hline G1 (PCG3) & 19.558 & 6.682 & 1.846 & 18.158 \\
\hline G2 (PCG1) & 19.138 & 6.956 & 1.934 & 18.482 \\
\hline G3 (PCG4) & 17.054 & 6.423 & 2.256 & 16.853 \\
\hline Average & 18.583 & 6.687 & 2.012 & 17.831 \\
\hline
\end{tabular}

Legend

Group : G1 (PCG3) : First classified and identified group. G2 (PCG1): Second classified and identified group. G3 (PCG4) :

Third classified and identified group. Descriptor*: Pe : Percentage of embryogenesis. 
Table 4. Classification of averages of the callogenic explants number, embryos number per embryogenic explant and embryogenesis percentage as a function of the explant nature.

\begin{tabular}{|l|l|l|l|l|l|l|}
\hline Explant* & Nexcal* & & Nemb* & & Pe* $^{*}$ & \\
\hline & Average* & CV (\%)* & Average* & CV (\%)* & Average* $^{*}$ & CV (\%)* \\
\hline Pt & $18.46 a$ & 19.03 & $8.181 \mathrm{a}$ & 15.41 & $85.973 a$ & 14.25 \\
\hline St & $19.10 \mathrm{a}$ & 18.61 & $0.985 \mathrm{~b}$ & 9.35 & $42.640 \mathrm{~b}$ & 18.84 \\
\hline
\end{tabular}

Legend

Explant*: Explant nature. Nexcal* : callogenic explants number. Nemb*: embryos number per embryogenic explants. $\mathbf{P e}^{*}$ : embryogenesis percentage. These are relevant and common variables identified from the two previously performed PCA. The two averages of each of the variables were separate using $Z$ test. Average* : Average of each of the relevant and common variables. $C V$ $(\%)^{*}$ : Coefficient of variation in percentage.

Typing of the genotypes and plantlets type in relation to the growth in the greenhouse

Concerning genotypes, in all the height (Height), diameter at collar (Diamcol), length of the greatest leaf (Lengleaf) and wide of the greatest leaf (Widgleaf) were identified as the most relevant descriptors. Therefore, they were used in the course of study to confirm the structuring of the genotypes in three groups provided by the Principal Component Analysis using the HCA. In contrast, the number of emitted leaves (Nbemleav) was eliminated from the study. From the PCA, all of five variables provided a structuring of genotypes in three groups: 1) G1 composed of C151-61, 2) G2 consisted of SCA6 and L233-A4 and 3) G3 constituted of L126-A3. From the HCA, C151-61 presented a better growth of four identified relevant descriptors. The genotype L126-A3 recorded a good development of length of the greatest leaf as well as that of diameter at collar, but low growth in height and wide of the greatest leaf (Table 4). Nevertheless, there was morphologically strong resemblance between groups G2 (SCA6/L233-A4) and G3 (L126-A3) revealed by the euclidian distance matrix (Figures 4, 6 and 8; Tables 5 and 7).
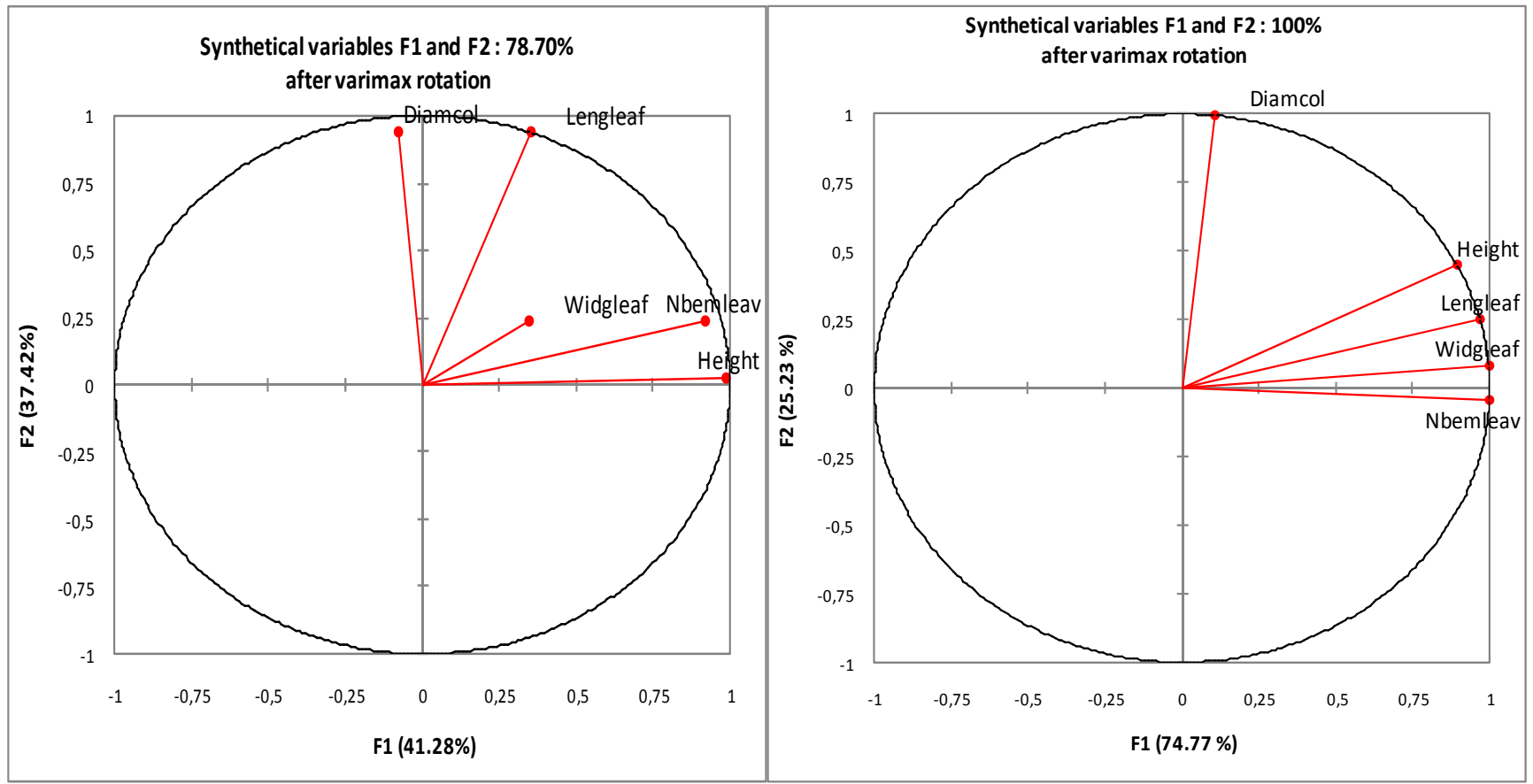

Fig 7

Fig 8 
Am. J. Biotechnol. Mol. Sci., 2011, 1(1): 17-29
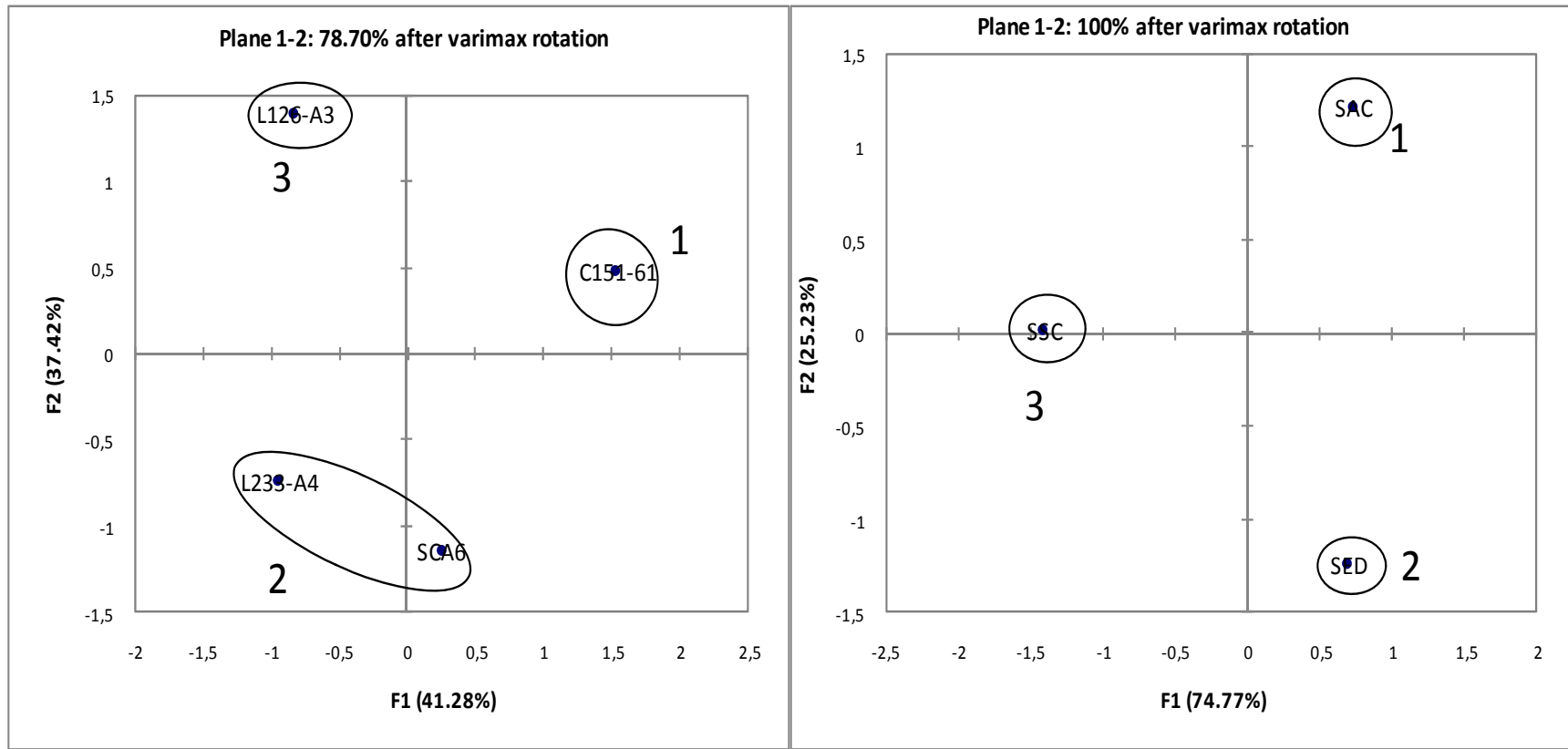

Fig 9

Fig 10

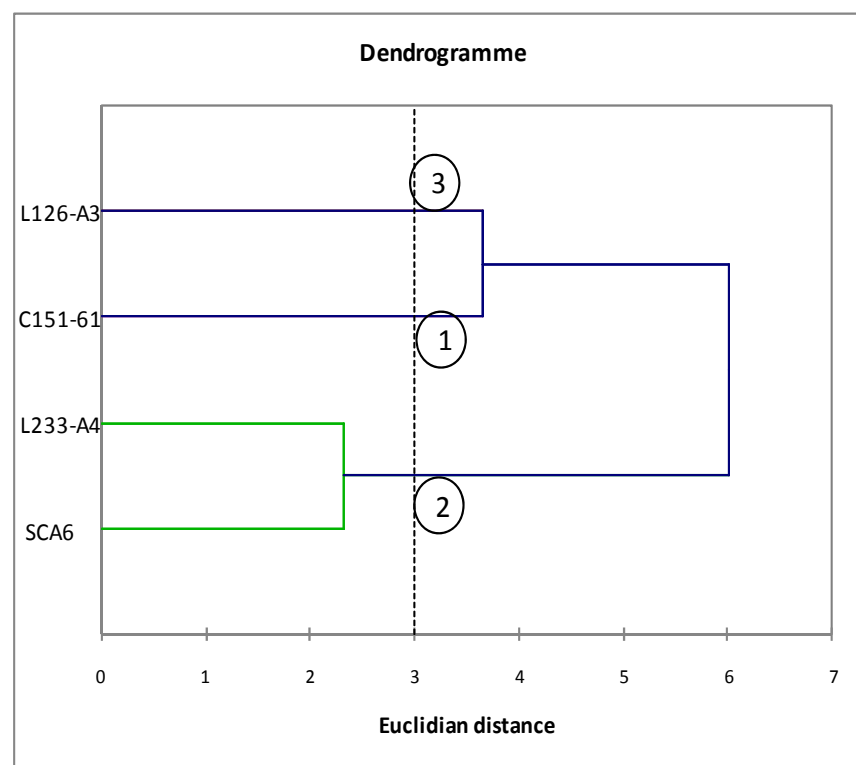

Fig 11

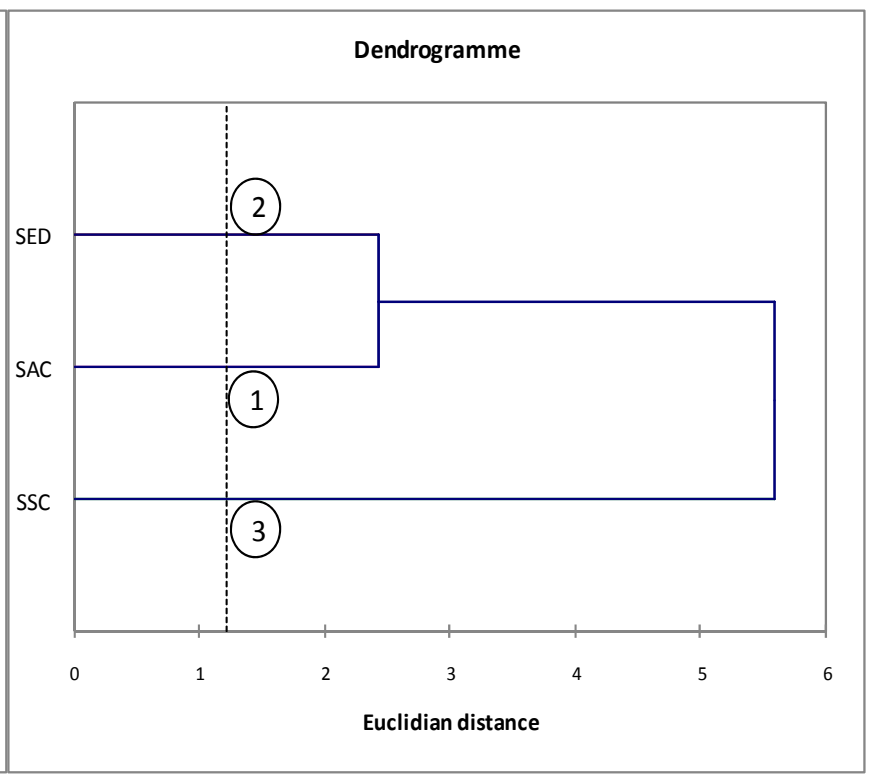

Fig 12 
Am. J. Biotechnol. Mol. Sci., 2011, 1(1): 17-29

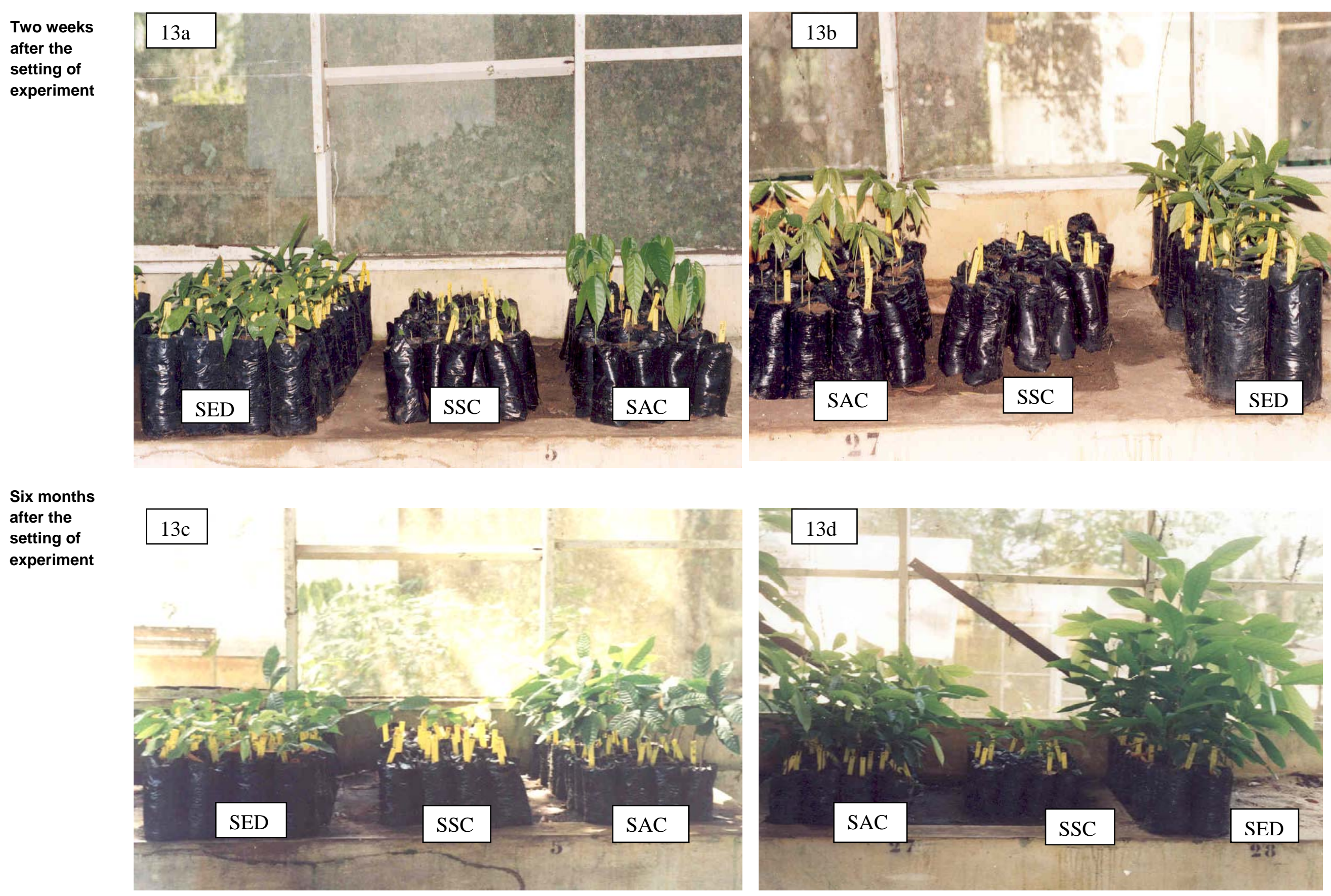


Am. J. Biotechnol. Mol. Sci., 2011, 1(1): 17-29
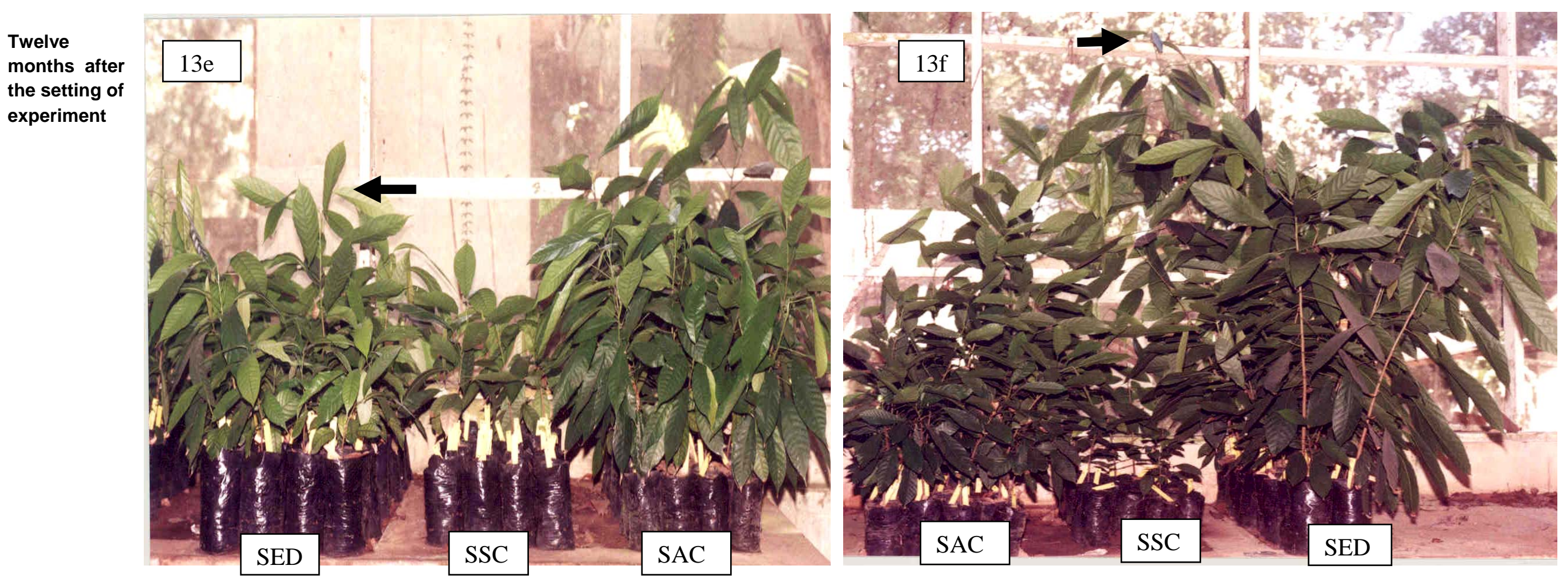

Fig 13 
Table 5: Hierarchical classification of the genotypes by means of the identified relevant descriptors.

\begin{tabular}{|l|c|c|c|c|}
\hline \multicolumn{1}{|c|}{ Descriptors* $^{*}$} & Height & Lengleaf & Widgleaf & Diamcol \\
\hline G1 (C151-61) & 27.418 & 22.242 & 4.977 & 0.553 \\
\hline G2 (SCA6, L233-A4) & 18.587 & 15.661 & 4.499 & 0.444 \\
\hline G3 (L126-A3) & 16.376 & 22.163 & 4.450 & 0.601 \\
\hline Average & 20.794 & 20.022 & 4.642 & 0.533 \\
\hline
\end{tabular}

Legend

Descriptors* : Height: Height. Lengleaf: Length of the greatest leaf. Widgleaf: Wide of the greatest leaf. Diamcol:

Diameter at collar.

Table 6: Hierarchical classification of the plantlets type from the identified relevant descriptors

\begin{tabular}{|l|c|c|c|c|}
\hline \multirow{2}{*}{ Group Descriptors } & Height & Nbemleav & Widgleaf & Diamcol \\
\hline G1 (SAC) & & & 5.188 & 0.559 \\
\hline G2 (SED) & 25.661 & 10.920 & 4.871 & 0.447 \\
\hline G3 (SSC) & 17.859 & 11.135 & 2.202 & 0.495 \\
\hline Average & 8.694 & 4.992 & 4.087 & 0.500 \\
\hline
\end{tabular}

Legend is as indicated under Table 4.

Table 7: Resemblance among genotype behaviours revealed through the euclidian distances of the proximity matrix from the HCA.

\begin{tabular}{|c|c|c|c|}
\hline & G1(C151-61) & G2(SCA6/L233-A4) & G3(L126-A3) \\
\hline G1(C151-61) & 0 & 3.138 & 2.685 \\
\hline G2(SCA6/L233-A4) & 3.138 & 0 & 2.636 \\
\hline G3(L126-A3) & 2.685 & 2.636 & 0 \\
\hline
\end{tabular}

Table 8: Resemblance among plantlet type behaviours through of euclidian distances of the proximity matrix from the HCA

\begin{tabular}{|c|c|c|c|}
\hline & G1(SAC) & G2(SED) & G3(SSC) \\
\hline G1(SAC) & 0 & 2.203 & 3.395 \\
\hline G2(SED) & 2.203 & 0 & 2.761 \\
\hline G3(SSC) & 3.395 & 2.761 & 0 \\
\hline
\end{tabular}


Regarding plantlets type, Height, Diamcol, Widgleaf and Nbemleav were proved to be better descriptors. Therefore, they were also used in the continuation of study to verify the validity of groups provided by the PCA by means of the HCA. On the contrary, the length of the greatest leaf (Lengleaf) was eliminated from the study. The five variables as a whole allowed the structuring of plantlets type in three groups from the PCA. First composed of control plantlets with cotyledons (SAC). Second constituted of SE-derived plantlets (SED). Third consisted of cotyledonamputed plantlets (SSC; Figure 6). This classification was confirmed by the use of four descriptors identified from the PCA using the HCA. Thus, plantlets bearing cotyledons (SAC) as control showed an excellent development of the height, length and wide of the greatest leaf as well as that of leaves flush. The SE-derived plantlets (SED) expressed a good growth with respect to height, length and wide of the greatest leaf as well as that of leaves flush, but a weak growth of the diameter at collar. On the contrary, cotyledon-amputed plantlets (SSC) displayed low growth of four evidenced relevant descriptors. Furthermore, there was high resemblance between SAC and SE highlighted by the euclidian distance (Figures 5, 7 and 9; Tables 6 and 8).

\section{DISCUSSION}

Three cocoa tree genotypes, especially two hybrids (L126-A3 and L233-A4) and one clone (C151-61) were both typed in relation to tissue culture and growth of their SE-derived plantlets and seedlings. So, their performances in vitro relatively to callogenesis and somatic embryogenesis as well as ex vitro in the greenhouse were assessed. Some works reported the production and regeneration of somatic embryos in plantlets (Li et al., 1998; Tan and Furtek, 2003; Issali, 2008a). Others reported the production of rooted microcuttings from SE-derived plantlets (Traore et al., 2003) and visually observed the behaviour of SE-derived plantlets in the greenhouse (Lopez-Baez et al., 1993; Li et al., 1998; Tan and Furtek, 2003). Our works showed that among the three typed genotypes, C151-61 globally both expressed better SE production and growth in the greenhouse.

The clone C151-61 expressed better calli and SE productions. It concerns the influence exerted by genotype on callogenesis and somatic embryogenesis. This influence was reported in Lopez-Baez et al., (1993), Li et al., (1998), Issali et al., (2008 b). So the response to callogenesis and SE depends on expression of genes (Chugh and Khurana, 2002; Santos et al., 2005). This genotype must be chosen for industrial production of the theobromin, chocolate aroma and cacao butter from the cell suspensions of calli. In the same way, this genotype must be used to produce and regenerate SE from the calli.

In tissue culture, both clones C151-61 and SCA6 were alike, while for vegetative development in the greenhouse, they were divergent. Both clones C15161 and SCA6 are genetically related individuals. Indeed, C151-61 come from back cross (SCA6 x ICS1) x ICS1 in which SCA6 and ICS1 were used as donor and recurrent parents, respectively (Lockwood and Gyamfi, 1979). This explains the low genetic distance between these two clones revealed by euclidian distance of the typological classification from the tissue culture. However, the divergence between the two relatively to vegetative development could be due to a better exposition of C151-61 at sun than SCA6 in the greenhouse. Sure enough, C15161's plantlets were situated to the east, whereas those of SCA6 were it to the west (Figures 3, 5, 9 and 11; Tables 2, 5 and 7).

Our results showed that the typology using at least two variables for describing of the populations is better than characterization by variable. The typology allowed the assessing of the degree of resemblance among individuals (Tables 7 and 8). Thus SE-derived plantlets globally displayed better growth in the greenhouse than cotyledon-amputed plantlets. This growth was comparable to that of control represented by seedlings bearing cotyledons (Table 8 ). Our results confirm the resemblance in behaviour between seedlings with cotyledons and SE-derived plantlets reported from visual observations in Li et al., (1998; Table 8). The reserves contained in cotyledons are important, but not essential at the growth. The SEderived plantlets do not slowly grow compared with seedlings with cotyledons as the visual observations have done think it. The two have the same growth speed in the greenhouse. It can be believed that the production costs of these two types of plantlets would be comparable. So the SE-derived plantlets must be used in the greenhouse or nursery.

The same clone C151-61 showed a better growth in the greenhouse in relation to the height, length of the greatest leaf and diameter at collar (Table 5). It also exists an effect of genotype on the expression of the growth of plantlets in the greenhouse. To our knowledge, no study reported the genotype effect related to growth in the greenhouse. Let us note that 
it exists a positive correlation between the growth of a seedling in the greenhouse or nursery on the one hand, and its vigour and productivity at field on the other hand (Braudeau, 1969). Therefore clone C15161 must be used in large field trials, all the more it well fructifies.

The PCG3 medium favoured the callogenesis, while PCG4 medium favoured the somatic embryogenesis. Thus media low hormonal concentration favour the callogenesis, whereas the ones high hormonal concentration favour the somatic embryogenesis. This once they contain the same hormonal balance. Using the characterization of the medium effect, similar result was reported in Issali et al., (2008 b). In short the PCG3 and PCG4 media must be used for calli and SE production, respectively.

For calli production, both staminodes and petals showed the same ability to produce the calli. In contrast with respect to SE production, sole petals expressed better embryogenic ability. This result is comparable to the one reported in Issali et al., (2008 b). The better embryogenic expression of petals was also reported in Söndahl et al., (1993), Lopez-Baez et al., (1993) and Issali et al., (2008b). In contrast, Alemanno, (1995), Li et al., (1998), Tan and Furtek, (2003) showed a higher embryogenic ability of staminodes. This might be due to potentiality inversion of these floral explants as a function of culture medium composition, especially the preparation by dissolution at the hot of the vitamin myo-inositol (Issali, 2008a). With respect to culture medium, hormonal balance as well as mineral and organic composition of culture media act on the expression of callogenesis and somatic embryogenesis (Li et al., 1998; Tan and Furtek, 2003).

\section{CONCLUSION}

Our study tested the hypothesis according to which the growth of SE-derived plantlets would be slow compared with that of plantlets bearing cotyledons. This might be due to lack of cotyledons containing the nutritive reserves in SE-derived plantlets. Actually, such a comparison showed strong proximity, and so strong resemblance between the two types of plantlets in relation to their growth in greenhouse. Therefore, their production cost would be comparable. We must continue to produce SEderived plantlets especially for superior genotypes.

\section{ACKNOWLEDGEMENTS}

We thank CNRA, IPGRI and BCCCA for their financial support. We are grateful to technical staff of the unit of in vitro culture of Central Biotechnology Laboratory of CNRA, especially Claude Assovi, Emmanuel Zran and Emmanuel Alle Ohoueu.

\section{REFERENCES}

Alemanno, L (1995). Embryogenèse somatique du cacaoyer Theobroma cacao L. : contrainte, progrès et perspectives. Thèse de Doctorat d'Université. Spécialité : physiologie végétale. Université Montpellier II. Sciences et Techniques du Languedoc. p 193.

Anonymous, (2004). Rapport annuel de la zone franc. Banque de France. Eurosystème. p 279.

Braudeau, J (1969). Le cacaoyer. G. P. Maisonneuve et Larose. Paris (V). p 304.

Bertrand, B., Agbodjan, A.K., (1989). Le bouturage orthotrope du cacaoyer, premiers résultats et perspectives. Café Cacao Thé. 33 : 147-156

Bertrand, B., Dupois, V (1992). Contribution à la mise au point du clonage du cacaoyer (Theobroma cacao L) par utilisation d'axes orthotropes. Contraintes et perspectives. Café Cacao Thé. 36 : 9-26.

Chugh, A., Khurana, P (2002). Gene expression during somatic embryogenesis-recent advances. Current sci. 25 september, 83 (6) : 715-730

Clement, D., Ngoran, J., Paulin, D., Lachenaud, Ph., Sounigo, O., Eskes, A (1996). Amélioration génétique du cacaoyer en Côte d'Ivoire : Nouvelle sortie variétale. In proceeding, douzième conférence internationale sur la recherche cacaoyère. Salvador (Brésil), 17-23 Nov. pp. 337-344.

Guiltinan, M.J., Maximova, S (2000). Recent advances in the tissue culture of cocoa from somatic embryos to bentwood gardens - a short review. In proceedings of the International Workshop on New Technologies and Cocoa Breedings. Ingenic. $16^{\text {th }}-17^{\text {th }}$ October 2000. Kota Kinabalu, Sabah, Malaysia. pp 157-162.

ICCO, (2000). Célébration du cacao. Organisation Internationale du Cacao (ICCO). Publié par K. P. Parteners in Publishing Ltd 2000. Imprimé et relié par Interprint, (Malte). p 115.

Issali, A.E., (2008a). Analyse de l'influence de quelques paramètres climatiques, phénologiques et génétiques sur l'embryogenèse somatique chez le cacaoyer : Theobroma cacao L. (Malvaceae). Thèse de Doctorat d'Université. Université de Cocody-Abidjan, Côte d'Ivoire. p 163.

Issali, A.E., Traoré, A., Koffi, K.E., Ngoran, J., Sangaré, A., (2008b). Characterization of callogenic and embryogenic abilities of some genotypes of cocoa 
(Theobroma cacao L.) under selection in Côte d'Ivoire. Biotech, 7: 51-58

Issali, A.E., Traoré, A., Konan, J.L., Mpika, J., Minyaka, E., Andi Kohi Ngoran, J†, Sangaré, A (2010). Relationship between five climatic parameters and somatic embryogenesis from sporophytic floral explants of Theobroma cacao L Afri. Journ. Biotech. Academic journals. 9 : 6614-6625.

Keli, J.Z., Assiri, A.A., Ngoran, K., Ngoran, J., Kebe, I.B (2005). Evolution de l'amélioration variétale de cacaoyer et de systèmes de production de la cacaoculture en Côte d'Ivoire. Sci. Nat. 2: 209-218.

Kouamanan oi Kouamanan, B (2001). Multiplication végétative du cacaoyer : contribution à la recherche de substrat de bouturage. Mémoire de Maîtrise. Protection des végétaux et de l'environnement. Université d'Abobo Adjamé. p 43.

Li, Z., Traoré, A., Maximova, S., Guiltinan, M.J (1998). Somatic embryogenesis and plant regeneration from floral explants of cocoa (Theobroma cacao L.) using Thidiazuron. In vitro Cell. Dev. Biol. Plant, 34: 293-299.

Lopez-Baez, O., Bollon, H., Eskes, A., Petiard, V. (1993). Embryogenèse somatique du cacaoyer Theobroma cacao L., à partir des pièces florales. Compte rendu. Acad. Sci. Paris, 316: 579-584.

Lockwood, G., Gyamfi, M.M.O (1979). The CRIG cocoa germplasm collection with notes on codes used in the breeding programme at Tafo and elsewhere. Cocoa Research Institut, Ghana. Technical Bulletin $n^{\circ}$ 10. $p$ 62.
Maximova, S.N., Alemanno, L., Young, A., Ferrière, N., Traoré, A., Guiltinan, M.J (2002). Efficiency, genotypic variability and cellular origin of primary and secondary somatic embryogenesis of Theobroma cacao L. In Vitro Cell. Dev. Biol. Plant, 38: 252-259.

Santos, M. de Oliveira., Romano, E., Yotoko K.S.C., Tinoco, M.L.P., Dias, B.B.A., Aragão, F.J.L (2005). Characterization of the cacao somatic embryogenesis receptor-like kinase (SERK) gene expressed during somatic embryogenesis. Plant Sci. 168 : 723-729.

Mossu, G (1990). Le cacaoyer. Editeurs Lienhart \& $C^{\text {ie }}$, Aubenas d'Ardèche, France. ACCT-CTCAR. p 159.

Söndahl, M.R., Lui; S., Bellato, C (1993) Cacao somatic embryogenesis. Acta horti. In vitro cult. 336 : 245-248.

Tan, C.L., Furtek, D.B (2003). Development of an in vitro regeneration system for Theobroma cacao from mature tissues. Plant Sci. 164:407-412.

Traoré, A., Maximova, S.N., Guiltinan, M.J (2003). Micropropagation of Theobroma cacao L. using somatic embryo-derived plants. In vitro Cell. Dev. Biol. 409: 1-7.

Whitlock, B.A., Bayer, C., Baum, D.A (2001). Phylogenetic relationships and floral evolution of the Byttnerioideae ("Sterculiacaea" or Malvaceae s.l.) based on sequences of the chloroplast gene, ndhF. John V; Freudenstein Editeur. System. Bot. 26 (2): 420-437.

Wood, G.A.R., Lass, R.A (1985). Cocoa.Tropical agriculture series. Longman. Fourth edition. p 620. 